\title{
Inovação no ensino superior: um estudo comparativo sobre a educação inovadora em um curso de graduação
}

\author{
Innovation in higher education: a comparative study on innovative education \\ in an undergraduate course
}

\author{
Keter Fagundes Bauermann ', Carlos Alberto Xavier Garcia ", Eduardo Pastorio III
}

\begin{abstract}
RESUMO
O presente estudo busca refletir sobre a inovação no ensino superior, ao considerar a mudança das propostas curriculares nos cursos de graduação, neste caso, no curso de Administração em uma Instituição de Ensino privada em São Gabriel/RS. Essa proposta proporciona ao aluno a experiência cobrada pelo mercado de trabalho. Diante deste contexto e importância buscou-se um estudo comparativo sobre a Educação Inovadora em uma Instituição de Ensino Superior (IES). Com um estudo de caso, realizou-se uma pesquisa exploratória-descritiva e de abordagem quali-quantitativa, através de método de observação e entrevistas buscou-se verificar qual a percepção dos alunos que migraram para o currículo da Graduação I e especificamente procurou-se identificar os objetivos do novo currículo da IES através dos documentos oficiais; discutir a prática pedagógica por meio de metodologias ativas de aprendizagem; e analisar a percepção que o professor tem do educando no processo de aprendizagem. Após o desenvolvimento da pesquisa, foi possível perceber que a nova metodologia de ensino, especificamente o componente curricular Projeto Integrador, preencheu uma lacuna no curso de graduação com relação a falta de interdisciplinaridade. Porém, existem muitos desafios a enfrentar com relação a comunicação do grupo e comprometimento constante dos alunos.
\end{abstract}

Palavras-chave: Currículo; Graduação Inovadora; Interdisciplinaridade.

\section{ABSTRACT}

The present study aims to reflect about the innovation in higher education, considering the change of curricular proposals in the graduation courses, in this case, in the administration course in an institution of private education in São Gabriel. This proposal provides to the student the experience charged by the labor market. Before this context and importance, we seek a comparative study about the Innovative Education in an Institution of Higher Education (IES). With a case study, we carried out an exploratory-descriptive research and of qualitativequantitative approach, through the method of observation and interviews we aimed to verify which the perception of the students that migrated for the curriculum of Graduation I is and specifically we seek to identify the objectives of the new curriculum of IES through the official documents; discuss the pedagogical practice by means of active

I Pós-Graduanda em Educação: Práticas de Ensino Interdisciplinares, Unipampa. E-mail: keterbauermann@hotmail.com. ORCID: https://orcid.org/0000-0002-9000-8959.

"Técnico em Assuntos Educacionais, Unipampa. E-mail: cxaviergarcia368@gmail.com. ORCID: https://orcid.org/0000-00019487-3600.

III Doutorando em Educação em Ciência, UFRGS. E-mail: eduardopastorio@hotmail.com. ORCID: https://orcid.org/0000-00032342-7851. 
methodologies of learning; and analyze the perception that the teacher has of the student in his learning process. After the development of the research, it was possible to perceive that the new teaching methodology, specifically the integrative project curricular component, filled a gap in the graduation course in relation to the lack of interdisciplinarity. However, there are many challenges to face in relation to the communication of the group and constant commitment of the students.

Keywords: Curriculum; Innovative Graduation; Interdisciplinarity.

\section{INTRODUÇÃO}

Este estudo parte do interesse em compreender o significado de Educação Inovadora. No decorrer da pesquisa identificamos alguns autores que defendem a prática educativa inovadora. Essa prática pode impulsionar mudanças significativas no ensino e aprendizagem. É essencial o desenvolvimento de atividades-interdisciplinares, para que tanto os alunos quanto os docentes percebam a necessidade do encontro das várias áreas científicas para compor o conhecimento, na Educação Básica ou no Ensino Superior.

Segundo Pinto (2011), a universidade é o local de formação de profissionais, a qual torna o ambiente favorável para enunciações de alternativas mais pedagógicas, que possibilita articular a teoria e a prática, a resolução de problemas reais, ao gerar ações críticas e refletidas a partir de experiências concretas.

As reformas curriculares fazem-se necessárias para atender às demandas das sociedades. O estudante quando termina a graduação sem ter vivenciado experiência reais, passa por um desafio muito grande quando vai exercer a sua profissão por não saber lidar com os problemas encontrados na sociedade, uma vez que a bagagem teórica não é o suficiente para enfrentar os obstáculos.

A inserção das metodologias ativas pode proporcionar mudanças curriculares significativas que aproximam os estudantes do contexto real, as quais permitam aos alunos desenvolverem o pensamento crítico, visão sistêmica, além de garantir a experiências de trabalhar com problemas reais. Assim, para que aconteça a mudança nas universidades é fundamental o comprometimento coletivo, o envolvimento dos gestores, alunos e os professores. 
A aproximação dos alunos com os problemas existentes na sociedade é de grande importância, pois, os alunos terão a oportunidade de desenvolver um pensamento crítico, ao alinhar o conhecimento teórico e prático, além de garantir maior segurança no momento em que estiver no exercício da profissão. É na ampliação dos horizontes, a partir de uma flexibilidade crítica que esse estudo se constrói.

Diante deste contexto e importância, realizou-se um estudo comparativo sobre a Educação Inovadora em uma IES, com o objetivo principal de verificar a percepção dos alunos que migraram para o currículo da Graduação I, e especificamente: identificar os objetivos do novo currículo da IES através dos documentos oficiais; discutir a prática pedagógica por meio de metodologias ativas de aprendizagem e analisar a percepção que o professor tem do educando em seu processo de aprendizagem.

Para a operacionalização desta investigação, buscou-se desenvolver uma pesquisa exploratória-descritiva, de abordagem quali-quantitativa mediante um estudo de caso. Para ilustrar como é possível propor mudanças na educação, o estudo comparativo possibilita vislumbrar que o ensino pode ser constituído de forma diferenciada, com o destaque das mudanças no currículo e as possibilidades de melhorias, ao considerar as necessidades da sociedade.

\section{ESTUDOS COMPARATIVOS}

No que se refere ao período da criação da educação comparada Ferreira justifica:

A Educação Comparada, como é evidente, ressente-se da evolução da reflexão pedagógica, do desenvolvimento científico e da expansão escolar. No seu aspecto nãosistemático encontram-se indícios de Educação Comparada já na Antiguidade, pois, Tucídides, Heródoto e Xenofonte fizeram comparações que nos permitem distinguir o modo educativo ateniense do espartano e a educação grega da egípcia e da persa (FERREIRA, 2007, p.127).

Conforme Silva (2016), o que parece mais significativo nesse processo é a capacidade de o estudo comparado estabelecer diversas perspectivas, abordagens e 
metodologias, compreensão dos fatos ou fenômenos educativos que compara, apresentase como um instrumento de conhecimento e de análise da realidade educativa.

Nas palavras de Filho (2004, p. 17), "Comparar é um recurso fundamental nas atividades de conhecer". Entretanto, é preciso considerar que, de certa maneira, há o acompanhamento de muitas mudanças no Ensino Superior. Essas mudanças "estão redesenhando o perfil das universidades contemporâneas [...]" LEITE (apud BORGES, 2013, p. 20). Uma vez que o professor e o estudante universitário, tem extrema importância para promover processos de inovação no Ensino Superior.

\section{METODOLOGIAS ATIVAS DE APRENDIZAGEM}

Conforme Hung (apud GUIMARÃES, 2019, p. 3), a aprendizagem ativa "reúne uma vasta gama de atividades educacionais, estratégias de ensino, métodos de ensino e qualquer abordagem pedagógica onde se pretende ativar ou desenvolver o pensamento crítico dos alunos no processo de aprendizagem".

Algumas práticas de ensino como: aprendizagem baseadas em projetos, aprendizagem baseadas em problemas, estudo de caso e aprendizagem entre pares ou times são características das metodologias ativas de aprendizagem, pois, envolvem os estudantes e os comprometem ativamente no desenvolvimento do processo ensino aprendizagem. As metodologias ativas de aprendizagem envolvem os estudantes e os comprometem ativamente em todos os processos de sua aprendizagem, ao proporcionar benefícios como habilidades de raciocínio avançadas, trabalho em equipe, motivação, novos recursos de aprendizagem e respeito aos diversos estilos de aprendizagem, faz com que ocorra desenvolvimento de aspectos como autonomia e tomada de decisão frente a uma situação problema (PINTO, 2011; MOREIRA 2019).

Wiebusch ao discorrer sobre metodologias ativas, comenta que: 
É preciso tornar as aulas mais dinâmicas e menos teóricas, contextualizadas, interdisciplinares, temáticas, dialógicas, problematizando desafios para que os estudantes possam construir o conhecimento, possam viver experiencias reais, promovendo uma aproximação da universidade com o mercado de trabalho e com a profissão dos estudantes, a fim de que tenham aprendizagens significativas no ensino superior. É na sala de aula que o estudante questiona, constrói argumentos, expõe ideias, esclarece as dúvidas, porque a aula universitária deve ser um ambiente interativo e formativo (2018, p. 156).

Na área de Administração, o método de caso de ensino simula a análise e a resolução de problemas gerenciais em sala de aula $(\mathrm{ROESCH}, 2019)$. O que motiva o aluno a pesquisar sobre uma determinada situação e apresentar os resultados em grupo. Os estudos de casos de diversas áreas trazidos para dentro da sala de aula proporciona o incentivo às práticas de ensino interdisciplinares, que possibilitam um maior comprometimento dos acadêmicos com os interesses da sociedade. Ao considerar o foco do estudo, na sequência discorre-se um pouco sobre interdisciplinaridade.

\section{INTERDISCIPLINARIDADE}

A interdisciplinaridade proporciona uma nova proposta de integração das várias áreas do conhecimento. A troca de informações, o diálogo e análises entre duas ou mais disciplinas produz um novo conhecimento. A atuação dos diversos sujeitos possibilita parcerias que conduzem a uma nova visão e uma nova maneira de caminhar, esse conhecimento é capaz de gerar um novo produto na educação, "tornando-a plena de significados" (FRAGOSO, 2008 p. 20).

No que se refere à prática interdisciplinar Fazenda justifica:

A prática interdisciplinar pressupõe uma desconstrução, uma ruptura com o tradicional e com o cotidiano tarefeiro escolar. O professor interdisciplinar percorre as regiões fronteiriças flexíveis onde o "eu" convive com o "outro" sem abrir mão de suas características, possibilitando a interdependência, o compartilhamento, o encontro, o diálogo e as transformações. Esse é o movimento da interdisciplinaridade caracterizada por atitudes ante o conhecimento (FAZENDA, 2008, p. 82).

A interdisciplinaridade, ainda, pode ser vista como uma mudança conceitual, proposta metodológica, teoria epistemológica ou modalidade de colaboração entre 
professores e pesquisadores. Também é vista como a aplicação de conhecimentos de uma disciplina em outra (AUDY, 2007).

Segundo Thiesen (2008), só haverá interdisciplinaridade no trabalho e na postura do educador se ele for capaz de compartilhar o domínio do saber, se tiver a coragem para abandonar o conforto da linguagem estritamente técnica e arriscar-se num domínio que é de todos e de que, portanto, ninguém é proprietário exclusivo.

A partir desses pressupostos teóricos é que buscamos compreender a proposta do novo currículo de graduação inovadora implementado em curso de graduação.

\section{GRADUAÇÃO INOVADORA}

De acordo com os autores Audy e Morosini (2007), a universidade capta os problemas que afligem a comunidade para buscar soluções e levantar alternativas, mas para isso deve haver um planejamento que seja estratégico e inovador.

No ensino superior, faz-se necessário rupturas com as práticas de ensino tradicionais. O avanço tecnológico e o acesso ao conhecimento, requer uma nova abordagem de ensinar, um ensino que seja capaz de motivar e instigar o interesse dos acadêmicos, para que tenham um engajamento acadêmico na sua instituição de ensino (WIEBUSCH, 2018).

No que tange ao profissionalismo Junges (2019), compreende que:

[...] para construir sua profissionalidade, o professor baseia-se em saberes provenientes da prática e da teoria, construídas no dia a dia da profissão, durante o seu desenvolvimento profissional. Não há ressignificação da prática sem a teoria e vice-versa, ambas dão sustentação à profissionalidade e à formação docente (JUNGES, p. 218. 2019).

No ensino superior, com o avanço das tecnologias e o acesso ao conhecimento, fazse necessária uma inovação na forma de ensinar, assim, promover rupturas nas práticas tradicionais, para motivar e instigar o interesse dos estudantes, com a promoção do engajamento acadêmico, e a superação da resistência da gestão, dos docentes e discentes. "Com relação ao desconhecido". Para isso a aplicação de uma nova metodologia de ensino centrada no aluno e na resolução de problemas, é o que tem sido apresentado. 


\section{METODOLOGIA}

Durante a elaboração desta pesquisa buscamos referências metodológicas, qualitativa com estudo de caso. Para Leal e Souza (2006), na pesquisa descritiva não há interferência do pesquisador, os fatos são somente observados, registrados e analisados. Na visão de Santos (1999, p. 26), pesquisa exploratória possibilita a aproximação de um tema que visa criar a familiaridade em relação a um fato ou fenômeno. "Busca-se essa familiaridade pela prospecção de materiais que possam informar ao pesquisador a real importância do problema". O que nos leva a pesquisa documental e de fontes impressas.

Conforme Deslandes (1994), a diferença de qualitativo-quantitativo é de natureza, porém, não se opõem e, sim, se completam, pois, a realidade abrangida por eles interage dinamicamente.

De acordo com Gil (1997), estudo de caso consiste em resumos narrativos de situações ocorridas nas entidades, em que as soluções ou críticas são apresentadas e discutida para elaboração da análise.

Como base da investigação utilizou-se o método de observação, por se tratar de um estudo de caso com acadêmicos do curso de graduação em administração de ambos os currículos. No objeto da pesquisa proposto investigou-se as 3 (três) turmas existentes na Instituição de Ensino, em que a observação foi feita em uma turma composta por 25 alunos pertencentes ao currículo graduação I, e aplicado o questionário com 2 (duas) turmas pertencentes ao currículo 41, com 10 alunos, ainda, este mesmo questionário foi aplicado na turma pertencente a graduação I, já observada anteriormente, através de um processo probabilístico aleatório, cujos dados foram coletados no período en tre outubro e novembro/2019. Posteriormente à coleta, os respectivos dados foram analisados pela autora.

Para a coleta de dados utilizou-se o modelo de Borges (2013) devidamente adaptados aos objetivos de estudo. O presente modelo norteia a busca por resultados do que consiste a nova metodologia de ensino, como é trabalhada em sala de aula e identifica os critérios. 


\section{RESULTADOS}

Ao realizar o estudo comparativo de ambos os currículos existentes na IES, observou-se a mudança que ocorre na grade curricular no primeiro semestre. Verificou-se a comparação do $1^{\circ}$ semestre em ambos os currículos, como apresentado abaixo:

\section{Tabela 1 - Quadro de Comparação do $1^{\circ}$ Semestre nos Currículos do Curso de Administração da IES}

\begin{tabular}{ll}
\hline Currículo 41 & Graduação - Módulo Profissão e Mercado \\
\hline Teoria Geral da ADM I & Competências pessoais e profissionais \\
Ética & Contabilidade aplicada a negócios \\
Produção textual & Gestão e estrutura organizacional \\
Informática & Matemática aplicada a gestão \\
Metodologia da Pesquisa & Projeto integrador - Profissão e Mercado \\
\hline
\end{tabular}

Fonte: (URCAMP, 2019).

Tabela elaborada por: Keter Bauermann.

Nas palavras de Fernandes e Freitas currículo é entendido como: "A definição do que a escola deve ensinar, de como ensinar e como avaliar, ou seja, do currículo escolar, é técnica, no sentido de que devemos ter uma formação pedagógica para fazê-lo, mas também é política" (FERNANDES E FREITAS apud ARCAS, 2017, p. 203).

A IES em estudo possui uma nova metodologia de ensino, chamada Graduação Inovadora (Graduação I). O novo currículo foi implantado, após dois anos de pesquisa acerca do ensino por competências, no primeiro semestre de 2019, a qual comtempla quase todos os cursos de graduação. Já no segundo semestre atendeu os cursos de Agronomia, Direito e Medicina Veterinária (URCAMP, 2019).

A metodologia de ensino do currículo Graduação I é composta pelo modelo de aprendizagem por competências, com componentes curriculares, competências pessoais e profissionais, de inovação, interdisciplinar, impactante, ilimitada e interativa. Ao proporcionar as experiências além da sala de aula (URCAMP, 2019). 
O projeto integrador é um componente curricular oferecido para que os alunos possam aplicar os conhecimentos estudados no módulo durante o semestre (URCAMP, 2019).

Cada projeto reúne acadêmicos em torno de um desafio sugerido por empresas ou instituições da comunidade. A cada semestre vencido pelo estudante, um novo projeto de integração com a realidade se soma às suas experiencias. Ao final do curso, o novo profissional formado pela graduação i tem a vantagem, de um conjunto de projetos que comprovam sua atuação prática, uma experiencia atualmente muito cobrada pelo mundo do trabalho (URCAMP, 2019).

Conforme consta no Programa de Desenvolvimento Institucional (PDI) 2018/2022, como política de inovação na perspectiva de ensino, destaca-se a reestruturação dos cursos de graduação por meio de uma nova matriz curricular, com o objetivo de otimizar os recursos e os docentes (PDI, 2019).

Dentre as ações adotadas, aponta-se:

[...]

1) implementação do núcleo de componentes curriculares semipresenciais, comuns a todos os cursos e campi;

2) implementação de núcleos de componentes curriculares comuns, ou seja, compartilhados, que reúnem cursos com afinidade;

3) revisão e atualização dos projetos pedagógicos de cursos, tendo em vista o atendimento das diretrizes curriculares; [...] (PDI, 2019, p. 63)

Ainda no PDI 2019, "o resultado do conjunto de medidas adotadas, especialmente em relação às novas tecnologias, permitiram o avanço para a adoção de metodologias ativas". Fica evidenciado no novo currículo, quando se observa a interação dos alunos com o mercado de trabalho, a prática do projeto integrador, especificamente, permite identificar a existência das metodologias ativas no curso.

Destaca-se que segundo Medeiros (2015), a ação curricular nada mais é que uma trajetória orientada que deve ser seguida pelos indivíduos, para que a finalidade já planejada seja alcançada. Destaca-se que segundo a pesquisa aplicada, por decisão da gestão da IES, a equivalência das disciplinas foi feita para alunos que cursavam até o $2^{\circ}$ semestre, por se tratar de disciplinas básicas e então ser mais fácil a equivalência ao $1^{\circ} \mathrm{e}$ 
$2^{\circ}$ módulo do novo currículo. Aqueles alunos que cursavam além do $3^{\circ}$ semestre permaneceram no currículo 41.

O critério para escolha do profissional que atua como orientador do projeto integrador é o professor que tiver pelo menos uma disciplina dentro do módulo e ter a flexibilidade de trabalhar todas as áreas abordadas nesse módulo.

Ao observar os alunos nas apresentações dos projetos integradores desenvolvidos durante o semestre, nota-se a autoavaliação do grupo referente a contribuição de cada aluno com a comparação do ambiente corporativo, ao saber lidar com as diferenças e limitações de cada indivíduo. "No ambiente corporativo não se escolhe o grupo, aprendemos a trabalhar com as diferenças". D.C (Aluna da Graduação I).

Dentre os desafios encontrados relatados pelos alunos, destacam-se a falta de comunicação e a aplicabilidade dos recursos ao desenvolver a pesquisa nas empresas. Conforme entrevista realizada com os professores que atuam em ambos os currículos, a qual foi fundamental para compreender o funcionamento da nova metodologia de ensino, R.V.C (Professora do curso de graduação) acrescenta: "Eu acredito que essa era a nossa lacuna anteriormente".

A fala de R. V. S. (Professora do curso de graduação), avalia o novo currículo:

A minha avaliação é satisfatória, pois, existia a necessidade de uma mudança no modelo de educação existente, que priorizasse metodologias ativas na construção do conhecimento dos acadêmicos, objetivando também reter esse público, que é extremamente interativo, na instituição de ensino. R. V. S.

Por meio de um questionário aplicado em ambas as turmas, foi possível identificar como a alternativa de número 06, que fala em: ao ensinar, traz exemplos do cotidiano. Já nos alunos do currículo graduação I, a questão mais optada foi a de número 02, Articulação dos temas de estudos entre as disciplinas do curso (Interdisciplinaridade).

Como complemento da análise, verifica-se que os alunos no currículo 41, possuem princípios da graduação inovadora, como as vivências e experiências adquiridas no cotidiano. Já os alunos com a nova metodologia de ensino possuem uma visão mais complexa, como a de enxergar o envolvimento das diversas áreas do conhecimento. 


\section{CONCLUSÕES}

A presente pesquisa tem como objetivo principal analisar a percepção dos alunos diante de uma nova proposta curricular. Ainda, a importância de um novo modelo curricular, que proporciona aos alunos uma graduação inovadora a partir de metodologias ativas de aprendizagem. Considera-se que ao refletir acerca das metodologias pedagógicas inovadoras, oportunizam-se novos caminhos e diferentes estratégias educacionais.

Em relação ao currículo da IES, verifica-se o novo modelo curricular, a graduação I, que introduziu o componente curricular chamado projeto integrador, o qual começou a fazer parte em todos os módulos do novo currículo, a partir do $1^{\circ}$ semestre de 2019.

Neste componente curricular o aluno aprende através de experiências reais e vai poder aplicar o conhecimento adquirido em sala de aula. Além disso, o projeto é capaz de unir as diversas áreas do conhecimento, neste processo o aluno desenvolve uma análise crítica, que o aproxima da situação real em que se encontra na sociedade.

As diversas áreas do conhecimento, em um mesmo módulo, é capaz de despertar no aluno uma visão sistêmica do que ele pode abordar, de maneira interdisciplinar, de modo que o aluno consiga envolvê-las em um conjunto de atividades exercidas no desenvolvimento da prática do projeto.

A proposta curricular ganhou uma dimensão ampla, ao trazer para dentro da universidade exigências do mercado de trabalho na comunidade em que os indivíduos estão inseridos. Além do comprometimento dos docentes no papel de educador.

Por meio das observações e percepções dos envolvidos no processo, foi possível identificar que o conceito inovação, busca criar práticas pedagógicas mais atrativas, que sejam de interesses dos estudantes. Desta forma, reforça a importância das ações da universidade, ao cumprir o seu papel em relação à responsabilidade social.

Diante deste cenário, o presente estudo teve como objetivo comparar os currículos existentes em uma IES, no curso de graduação em administração. A pesquisa aplicada 
possibilitou analisar a percepção dos alunos em ambos os currículos, os quais apontaram os desafios e as perspectivas dentro do curso.

Os resultados evidenciaram a necessidade da participação do corpo docente e a extrema importância de o grupo trabalhar de forma interdisciplinar. Só assim, a nova proposta de ensino atenderá os objetivos propostos pela IES e proporcionará o retorno que os alunos esperam.

\section{AGRADECIMENTOS}

Aos professores e professoras do curso de Especialização em Práticas de Ensino Interdisciplinares de Ensino - EDUINTER, pelos ensinamentos que me proporcionaram um olhar para com a educação com zelo e carinho.

A todas as discentes e docentes da Universidade da Região da Campanha Campus São Gabriel/RS, que contribuíram com suas respectivas considerações para com o questionário aplicado.

A Ms. Rosana Veiga do Canto, coordenadora do curso de administração, pelos esclarecimentos acerca dos processos gerais, paciência e dedicação para a construção deste trabalho.

\section{REFERÊNCIAS}

ARCAS, Paulo Henrique. Avaliação na Educação. Londrina: Editora e Distribuidora Educacional S.A, 2017.

AUDY, Jorge Luis Nicolas; MOROSINI, Marília Costa. Inovação e Interdisciplinaridade na Universidade. Porto Alegre: EDIPUCRS, 2007. 526 p. Disponível em: http://www.pucrs.br/edipucrs/inovacaoeinterdisciplinaridade.pdf. Acesso em: 28/11/2019.

BORGES, Daniele Simões. Das inovações no ensino ao ensino inovador: complexidade e emergências no ensino universitário. Dissertação de Mestrado, FURG, Rio Grande, 2013. Disponível em: http://repositorio.furg.br/bitstream/handle/1/4795/Daniele\%20Sim\%C3\%B5es\%20Borges.pdf? sequence $=1$. Acesso em: 12/11/2019. 
DESLANDES, Suely Ferreira et al. Pesquisa Social: teoria, método e criatividade. Petrópolis, RJ: Vozes, 1994.

FAZENDA, Ivani et al. O que é interdisciplinaridade? São Paulo, Cortez, 2008.

FERREIRA, ANTONIO GOMES. O Sentido da Educação Comparada: Uma compreensão sobre a construção de uma identidade. Educação, Porto Alegre, 2007. Disponível em: http://revistaseletronicas.pucrs.br/ojs/index.php/faced/article/view/2764/2111. Acesso em: 20/10/2019.

FILHO, Manoel Bergstrom Lourenço. Educação Comparada. 3 ed. Brasília, MEC/Inep, 2004.

FRAGOSO, Maria Isabel Pedroso. O projeto Interdisciplinar como diferencial motivador num contexto de aprendizagem. Dissertação de Mestrado, São Paulo, 2008. Disponível em: http://tede.mackenzie.br/jspui/bitstream/tede/2008/1/Maria\%20lsabel\%20Pedroso\%20Fragos o.pdf. Acesso em: 20/10/2019.

GIL, Antônio Carlos. Metodologia do ensino superior. $3^{\circ}$ ed. São Paulo: Atlas, 1997.

GUIMARÃES, Júlio Cesar Ferro de. Formação Docente: Uso de Metodologias Ativas Como Processo Inovador de Aprendizagem para o Ensino Superior. XVI Mostra de Iniciação Científica, Pós-Graduação, Pesquisa e Extensão. Programa de Pós-graduação em Administração - UCS. Disponível em: http://www.ucs.br/etc/conferencias/index.php/mostraucsppga/xvimostrappga/paper/viewFile/ 4740/1606. Acesso em: 20/11/2019.

JUNGES, Kelen dos Santos; BEHRENS, Marilda Aparecida. Uma formação Pedagógica inovadora como caminho para a construção de saberes docentes no Ensino Superior. Educar em Revista. Disponível em: http://www.scielo.br/pdf/er/n59/1984-0411-er-5900211.pdf. Acesso em: 02/09/2019.

LEAL, Alzira Elaine Melo; SOUZA, Carlos Eduardo Gerzson de. Construindo o conhecimento pela pesquisa: orientação básica para elaboração de trabalhos científicos. Santa Maria: Sociedade Vicente Palloti, 2006.

MEDEIROS, Marcossuel de. Um olhar crítico sobre currículo: Um estudo do currículo no contexto de instituições escolares do município de Caicó/RN. Monografia apresentada ao Curso de Pedagogia. UFRN, Caicó, $2015 . \quad$ Disponível em:https://monografias.ufrn.br/jspui/bitstream/123456789/1814/6/Um\%20olhar\%20cr\%C3\%A Dtico_Monografia_Medeiros.pdf. Acesso em: 10/06/2019.

MOREIRA, Jonathan Rosa. Prática Pedagógica baseada em metodologia ativa: aprendizagem sob a perspectiva do letramento informal para o ensino na educação 
profissional. Disponível em: http://revista.faculdadeprojecao.edu.br/index.php/ Projecao5/article/view/722/608. Acesso em: 01/07/2019.

PINTO, Ivone Maciel. Docência Inovadora na Universidade. Tese apresentada ao curso de Doutorado. UFG, Goiânia, 2011. Disponível em: https://ppge.fe.ufg.br/up/6/ o/tese_ivone_final.pdf?1335464561. Acesso em: 15/06/2019.

PDI, Plano de Desenvolvimento Institucional. Disponível em: https://www.urcamp.edu.br/storage/attachments/attachments/15b71c928434a11534183720.p df. Acesso em: 12/11/2019.

ROESCH, Sylvia Maria Azevedo. Casos de Ensino em Administração. Notas Sobra a Construção de Casos para Ensino. Disponível em: http://www.scielo.br/pdf/rac/v11n2/a12v11n2.pdf. Acesso em: 10/11/2019.

SANTOS, Antônio Raimundo dos. Metodologia Científica: a construção do conhecimento. Rio de Janeiro, 1999.

SILVA, Fabiany de Cássia Tavares. Estudos comparados como método de pesquisa: a escrita de uma história curricular por documentos curriculares. Revista Brasileira de Educação, v. 21, no 64. Universidade Federal do Mato Grosso do Sul, Campo Grande, MS, 2016. Disponível em: http://www.scielo.br/pdf/rbedu/v21n64/1413-2478-rbedu-21-64-0209.pdf. Acesso em: 10/11/2019.

THIESEN, Juares da Silva. A interdisciplinaridade como um movimento articulador no processo ensino-aprendizagem. Revista Brasileira de Educação. V. 13, n 39. UESC, 2008. Disponível em: http://www.scielo.br/scielo.php?script=sci_arttext\&pid=S141324782008000300010. Acesso em: 01/07/2019.

URCAMP, Universidade da Região da Campanha. Disponível em: https://www.urcamp.tche.br/. Acesso em: 10/11/2019.

WIEBUSCH, Andressa; LIMA, Valderez Marina do Rosário. Inovação nas práticas pedagógicas no Ensino Superior: possibilidades para promover o engajamento acadêmico. PUCRS, 2018. em: http://revistaseletronicas.pucrs.br/ojs/index.php/porescrito/article/view/31607/17726. Acesso em: 20/11/2019. 